\title{
Rapid Homeostatic Plasticity of Intrinsic Excitability in a Central Pattern Generator Network Stabilizes Functional Neural Network Output
}

\author{
Joseph L. Ransdell, ${ }^{1}$ Satish S. Nair, ${ }^{2}$ and David J. Schulz ${ }^{1}$ \\ ${ }^{1}$ Division of Biological Sciences and ${ }^{2}$ Department of Electrical and Computer Engineering, University of Missouri-Columbia, Columbia, Missouri 65211
}

\begin{abstract}
Neurons and networks undergo a process of homeostatic plasticity that stabilizes output by integrating activity levels with network and cellular properties to counter longer-term perturbations. Here we describe a rapid compensatory interaction among a pair of potassium currents, $\mathrm{I}_{\mathrm{A}}$ and $\mathrm{I}_{\mathrm{KCa}}$, that stabilizes both intrinsic excitability and network function in the cardiac ganglion of the crab, Cancer borealis. We determined that mRNA levels in single identified neurons for the channels which encode $\mathrm{I}_{\mathrm{A}}$ and $\mathrm{I}_{\mathrm{KCa}}$ are positively correlated, yet the ionic currents themselves are negatively correlated, across a population of motor neurons. We then determined that these currents are functionally coupled; decreasing levels of either current within a neuron causes a rapid increase in the other. This functional interdependence results in homeostatic stabilization of both the individual neuronal and the network output. Furthermore, these compensatory increases are mechanistically independent, suggesting robustness in the maintenance of neural network output that is critical for survival. Together, we generate a complete model for homeostatic plasticity from mRNA to network output where rapid posttranslational compensatory mechanisms acting on a reservoir of channels proteins regulated at the level of gene expression provide homeostatic stabilization of both cellular and network activity.
\end{abstract}

\section{Introduction}

The balance of plasticity and stability in generating appropriate output is a matter of fundamental importance in the nervous system across all functional levels. These processes occur even at the most fundamental level, the excitability of individual neurons, and yet little is known about mechanisms governing these processes (Marder, 2011; Turrigiano, 2011). Early work identified such processes of "homeostatic plasticity" of intrinsic excitability (LeMasson et al., 1993; Turrigiano et al., 1994, 1995; Golowasch et al., 1999), but subsequent focus more intensely shifted to determining how stabilization of synapses is accomplished through synaptic scaling (Turrigiano, 2012). Recently, a resurgence of interest in plasticity of intrinsic excitability has accompanied work on synaptic scaling (Debanne and Poo, 2010; Misonou, 2010; Turrigiano, 2011).

Fewer studies on homeostatic plasticity have considered functional compensation in the context of endogenous network activity. The most dramatic example may be complete recovery of motor network output following loss of central inputs as a result

Received April 20, 2012; revised May 23, 2012; accepted May 25, 2012.

Author contributions: J.L.R. and D.J.S. designed research; J.L.R. performed research; J.L.R., S.S.N., and D.J.S. analyzed data; S.S.N. and D.J.S. wrote the paper.

This work was supported by a Craig H. Neilsen Foundation Grant 83026 (to D.J.S.), the Missouri Spinal Cord Injuries Program (to D.J.S.), and Department of Defense-Congressionally Directed Medical Research Programs Exploration-Hypothesis Development Award SC090555 (to D.J.S.).

The authors declare no competing financial interests.

Correspondence should be addressed to Dr. David J. Schulz, University of Missouri, Department of Biological Sciences, Columbia, M0 65211. E-mail: schulzd@missouri.edu.

DOI:10.1523/JNEUROSCI.1945-12.2012

Copyright $\odot 2012$ the authors $\quad 0270-6474 / 12 / 329649-10 \$ 15.00 / 0$ of changes in conductances in the crustacean stomatogastric ganglion (STG) (Thoby-Brisson and Simmers, 1998, 2002). Knockouts of $\mathrm{K}^{+}$channels in mice have been shown to have modest effects on phenotype and cellular output as a result of compensation by other $\mathrm{K}^{+}$channels (Guo et al., 2005; Nerbonne et al., 2008). Additionally, overexpression of A-type $\mathrm{K}^{+}$channels in STG neurons results in little change in neuronal output as a result of compensatory increases in H-current (MacLean et al., 2003, 2005). However, these examples feature mechanisms that act over longer time scales of days to weeks. While initial reports of plasticity in intrinsic excitability were found over shorter time scales (Desai et al., 1999; Golowasch et al., 1999), surprisingly little is known of the role these mechanisms may play in shortterm ongoing activity of biologically intact networks, specifically where an expectation for rapid conservation of output could be argued, such as in central pattern generators (CPGs).

Compensation in CPG circuits may be inferred from the fact that normal populations of unmanipulated motor neurons of two invertebrate CPGs, the cardiac and stomatogastric ganglia, show correlations in expression levels of mRNAs for ion channels (Schulz et al., 2007; Tobin et al., 2009) and membrane conductances (Khorkova and Golowasch, 2007; Temporal et al., 2012). One relationship detected in previous work (Tobin et al., 2009) is a positive correlation between $B K K C a$ and shaker mRNA levels in neurons of the cardiac ganglion. These channels encode calciumactivated and A-type $\mathrm{K}^{+}$currents, respectively. However, it is unclear how a neuron would use two similar hyperpolarizing conductances additively to generate or maintain its output. In this study we focused on elucidating the functional relationship between these two conductances in motor neurons of the crab 
cardiac ganglion. We discovered a striking discrepancy in the relationship of these channels across functional levels: mRNAs for these channels were positively correlated, while their conductances were negatively correlated. Therefore, we propose a comprehensive hypothesis for plasticity of excitability from mRNA to network output whereby rapid compensation provides stabilization of cellular and network activity.

\section{Materials and Methods}

Preparations. Cancer borealis crabs of either sex were purchased and shipped overnight from The Fresh Lobster Company (Gloucester, MA). Crabs were kept between $24 \mathrm{~h}$ and 2 weeks in artificial sea water at $12^{\circ} \mathrm{C}$ before use. Crabs were anesthetized in ice for $15 \mathrm{~min}$ before the dissection. The dissection took place in chilled physiological saline comprised of $440 \mathrm{~mm} \mathrm{NaCl}, 26 \mathrm{~mm} \mathrm{MgCl} 213 \mathrm{~mm} \mathrm{CaCl}_{2}, 11.2 \mathrm{~mm}$ Trizma base, 11 $\mathrm{mm} \mathrm{KCl}$, and $5 \mathrm{~mm}$ maleic acid $(\mathrm{pH}=7.4)$. When we wanted to isolate individual large cells, individual strands of bulking nylon were used to ligate the nerve on both sides of a large cell soma. To impale large cells, each cell was individually desheathed using a tungsten needle (Fine Science Tools).

Quantitative single-cell RT-PCR. Quantitative RT-PCR was performed as previously described (Schulz et al., 2006a; Tobin et al., 2009). Primers specific for real-time PCR detection of shal, $B K K C a$, shab, and shaker using Sybr Green were developed and designed using Primer3 software and are the same as previously reported (Schulz et al., 2006a; Tobin et al., 2009). Briefly, total RNA was isolated using RNeasy micro column-based RNA extraction kit (Qiagen), reverse transcribed using SuperScript III reverse transcriptase (Invitrogen), and used as a template in real-time RT-PCR with Sybr Green (SABiosciences) in a RotorGene 3000 real-time PCR machine (Corbett Research). Previous studies have determined that in LC motor neurons, correlations can be equally well detected among channel mRNA levels with and without normalization of real-time results to $18 \mathrm{~S}$ rRNA (Tobin et al., 2009). Values reported here are total copy numbers from a single neuron, and are not normalized with respect to $18 \mathrm{~S}$ levels.

Pharmacology. Pharmacological blockers were dissolved in physiological saline and perfused onto the cardiac ganglion using a Rabbit peristaltic pump (Rainin Instruments) at a rate of $1.5 \mathrm{ml} / \mathrm{min}$ or added to the preparation from a stock solution via pipette. The following pharmacological agents were used: tetraethylammonium dissolved in saline at 25 $\mathrm{mm}$, 4-aminopyridine dissolved in saline at $1 \mathrm{~mm}$, cadmium chloride dissolved in saline at $250 \mu \mathrm{M}$ (Acros Organics), tetrodotoxin dissolved in saline at $1 \mu \mathrm{M}$ (Alomone Laboratories), BAPTA-AM dissolved DMSO and applied at $30 \mu \mathrm{M}$ in saline, ryanodine dissolved DMSO and applied at $100 \mu \mathrm{M}$ in saline, staurosporine dissolved in DMSO and applied at $5 \mu \mathrm{M}$ in saline, okadaic acid dissolved in DMSO and applied at $500 \mathrm{~nm}$ in saline (Ascent Scientific), cyclosporine A dissolved in DMSO and applied at 2 $\mu \mathrm{M}$ in saline (Tocris Biosciences). All DMSO applications resulted in a final concentration of DMSO that was $<1 \%$ (range: $0.000025 \%$ to $0.5 \%$ ).

Pharmacological agents used to investigate intracellular mechanisms involved in the compensatory response (BAPTA-AM, ryanodine, okadaic acid, cyclosporine A, staurosporine) were applied to the cardiac ganglion $1 \mathrm{~h}$ prior ( $2 \mathrm{~h}$ prior with ryanodine) to the application of the blocker which caused the compensation (TEA or 4AP). A cell or preparation was exposed only to one channel blocker type (TEA or 4AP) for a given experiment.

Current measurements. All experiments were performed in physiological saline cooled to $12^{\circ} \mathrm{C}$. To measure current magnitudes and activation properties, two-electrode voltage-clamp (TEVC) experiments were performed by impaling a large cell with two glass electrodes filled with $3 \mathrm{M}$ $\mathrm{KCl}$ (8-17 $\mathrm{M} \Omega$ resistance) and an Axoclamp 2A amplifier (Molecular Devices). All recordings were made from anterior large cell somata; action potential conductances were blocked (unless noted otherwise) by tightening thread ligatures on both sides of the large cell soma, preserving space clamp. TEVC protocols were created, driven and recorded with clampex 9.2 software (Molecular Devices). Current recordings were analyzed with Clampfit 9.2 software (Molecular Devices). Current and voltage traces were sometimes filtered with a lowpass boxcar filter using 7 smoothing points. Most voltage clamps were modified from those used previously in STG preparations (Golowasch and Marder, 1992; Khorkova and Golowasch, 2007; Temporal et al., 2012). High threshold potassium current $\left(\mathrm{I}_{\mathrm{HTK}}\right)$ magnitude was measured using a leak subtracted TEVC protocol with a holding potential of $-40 \mathrm{mV}$ and 16 voltage steps from $-55 \mathrm{mV}$ to $+20 \mathrm{mV}$ ( $5 \mathrm{mV}$ intervals). A-type potassium current $\left(\mathrm{I}_{\mathrm{A}}\right)$ magnitude was measured by subtracting the $\mathrm{I}_{\mathrm{HTK}}$ current traces from a TEVC protocol that is identical except for a holding potential of $-80 \mathrm{mV}$. Calcium-activated potassium current $\left(\mathrm{I}_{\mathrm{KCa}}\right)$ was isolated by subtracting postcadmium $\left(250 \mu \mathrm{M} \mathrm{CdCl}_{2}, 1 \mathrm{~h}\right) \mathrm{I}_{\mathrm{HTK}}$ current traces from precadmium $\mathrm{I}_{\mathrm{HTK}}$ current traces (isolating the cadmium-sensitive outward current). Delayed rectifier potassium current $\left(\mathrm{I}_{\mathrm{Kd}}\right)$ was isolated using the $\mathrm{I}_{\mathrm{HTK}}$ TEVC protocol after cadmium exposure $\left(250 \mu \mathrm{M} \mathrm{CdCl}_{2}\right.$, $1 \mathrm{~h})$. All current magnitude measurements were taken at $0 \mathrm{mV}$ on an I-V plot made from the current traces.

Large cell excitability and network output. Cardiac network output was monitored with a single intracellular recording (using same equipment as TEVC protocols) taken from one of the three anterior large cells and an extracellular differential recording made with a model $1700 \mathrm{~A}-\mathrm{M}$ Systems $\mathrm{AC}$ amplifier and two stainless steel wires; one placed inside and one outside a vaseline well located around the central nerve of the CG (see Fig. 1). Pharmacological blockers (TEA or 4AP) were perfused on the entirety of the CG with the exception of the four small cell and two posterior large cell somata. These cells were isolated from the perfusion by a vaseline well placed around these cells and the posterior branch point containing regular physiological saline (see Fig. 1). Using this experimental configuration we monitored the effect of the LC compensatory response (isolated to the best of our ability from small cells) in the context of the functioning network. Network activity was recorded in $10 \mathrm{~min}$ intervals before and during blocker perfusion. These recordings were analyzed using Spike2 v6.00 software (Cambridge Electronic Design).

LC intrinsic excitability was examined under similar conditions except $10^{-6} \mathrm{M}$ TTX saline was placed in the vaseline well around the four small cell and two posterior LC somata. This eliminated spontaneous network activity and small cell excitatory input into the anterior LCs. Excitability in the anterior LCs was then monitored using two-electrode currentclamp (TECC) protocols run before and every 5 min after TEA or 4AP perfusion. TECC protocol was a six step depolarizing current injection (from 1 to $6 \mathrm{nA}$ ) lasting six seconds per step and six seconds between steps.

Statistics. All statistical tests were performed with SigmaPlot v11.0 (Systat, Aspire Software International). All data were confirmed to be of normal distribution as required by statistical analyses used. Relationships between channel mRNAs and ionic currents were analyzed using Pearson's correlation test, and coefficients of determination were calculated from the resulting correlation coefficients. In the case of Figure 2, $C$ and $D$, a potential outlier was identified that could be anchoring a false positive for the Pearson's test (see arrows). Analyses on these datasets were performed both with and without the data point in question and both results reported. Bonferroni corrections were used for multiple comparisons in the correlation analyses, and the $p$ value adjusted to 0.017 for statistical significance (three comparisons each for mRNA and ionic currents). Changes in current magnitude before and after pharmacological block were analyzed in one of two ways. Raw currents were analyzed before and after blockade via paired $t$ tests, and these are reported in Figure 3. In Figure 5, significant changes in a current relative to baseline were expressed as a percent change from zero, and analyzed via onesample $t$ test with the hypothesized population mean set to 0 . Overall changes in burst duration, spikes per burst, and spike frequency within the burst reported in Figure 4 were analyzed with repeated-measures ANOVA.

\section{Results}

The crustacean cardiac ganglion as a model for central pattern generator network activity

The rhythmic pumping of the heart in decapod crustaceans such as the crab, Cancer borealis (our model organism), is neurogenic 


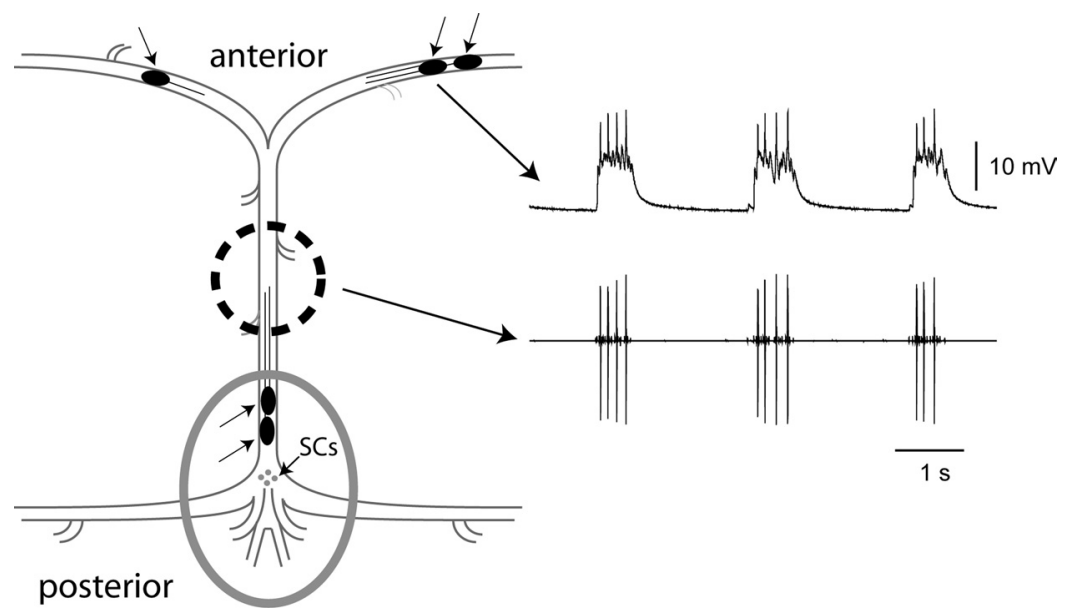

Figure 1. The crustacean cardiac ganglion. When dissected from the animal, the cardiac ganglion can be pinned flat and simultaneous recordings of network activity and intracellular recordings can be obtained. Five large cell somata (dark ovals marked with arrowheads) are distributed throughout the ganglion. Individual or pairs of large cells can be isolated for voltage clamp with thread ligature, or for pharmacological treatment with a vaseline well. The recording shows a simultaneous extracellular and intracellular recording of network activity. The bursting of the network is seen at the site indicated by the dotted circle and corresponds to the extracellular (bottom) trace. Burst output of a single $\mathrm{LC}$ motor neuron is seen in the top trace, taken from an intracellular recording of a $\mathrm{LC}$ soma. This rhythmic motor activity corresponds directly to the contraction of the single-chambered crab heart muscle, showing an in vitro maintenance of biological network activity. The gray oval represents a vaseline well used in pharmacological blocker experiments. During measurements of individual LC excitability (Fig. $4 A$ ), this well was used to apply TTX to the small cell pacemaker neurons (SCS, small gray circles) to silence the network activity but preserve output capability in anterior LCs. During measurements of compensation during ongoing network activity, this cell was used to protect SCs from blocker application in the bath (Fig. 4B).

in nature, and under the control of a simple central pattern generator network called the cardiac ganglion (Alexandrowicz, 1932) (Fig. 1). The ganglion consists of only nine neurons: four "small cell" interneurons (SCs) that generate the pacemaker activity and five "large cell" motor neurons (LCs) that innervate the heart musculature (Hartline, 1967; Tazaki and Cooke, 1983c). The SCs of the cardiac ganglion are endogenous oscillators, i.e., they undergo spontaneous and rhythmic generation of a depolarizing wave of membrane potential that leads to a bursting phenotype of multiple spikes per burst (Tazaki and Cooke, 1983b; Cooke, 2002). The LCs of the CG produce bursts of action potentials as a result of synaptic pacemaker input from the SCs, ultimately leading to muscle contraction (Hartline, 1967; Tazaki and Cooke, 1979, 1983a,c; Berlind, 1989). The behavioral output of the ganglion represents a direct correlation of the influence of LCs on heart muscle (Sakurai and Wilkens, 2003; García-Crescioni et al., 2010), and thus a direct measure of heart activity. Yet the entire network can be dissected out intact, and maintained in physiological saline for extended periods of recording while continuing to produce its endogenous rhythmic output. The motor neurons are all individually identifiable, and due to their distributed nature within the ganglion (Fig. 1), we can perform pharmacological manipulations on one or multiple motor neurons, either in isolation or in the intact, functional network (Tazaki and Cooke, 1983a; Cooke, 2002). The underlying burst potentials of the LCs represent functional output at the motor neuron level, and our preliminary modeling studies show how the simplicity of this model system can be used to study functional implications of the relationships between mRNAs and ionic conductances on cellular output (Ball et al., 2010; Franklin et al., 2010).

Relationship between $\mathrm{I}_{\mathrm{A}}$ and $\mathrm{I}_{\mathrm{KCa}}$ in a population of large cell motor neurons

Potassium currents were measured using protocols developed for the STG cells of the same species (Golowasch and Marder, 1992).
The total outward current of LC motor neurons consists primarily of three $\mathrm{K}^{+}$ currents (Fig. 2B) (Golowasch and Marder, 1992): A-type transient $\mathrm{K}^{+}$current $\left(\mathrm{I}_{\mathrm{A}}\right)$, calcium-activated $\mathrm{K}^{+}$current $\left(\mathrm{I}_{\mathrm{KCa}}\right)$, and delayed rectifier $\mathrm{K}^{+}$current $\left(\mathrm{I}_{\mathrm{Kd}}\right)$. $\mathrm{I}_{\mathrm{KCa}}$ and $\mathrm{I}_{\mathrm{Kd}}$ can be found in one combined current trace elicited from holding potentials at $-40 \mathrm{mV}$ or higher, and is termed here as the high-threshold $\mathrm{K}^{+}$current $\left(\mathrm{I}_{\mathrm{HTK}}\right)$, while the A-type current can be measured by subtracting $\mathrm{I}_{\mathrm{HTK}}$ from the total outward current elicited from a holding potential of $-80 \mathrm{mV}$.

We first examined the relationships among mRNA levels in single identified LC motor neurons for three channel genes that correspond to these three $\mathrm{K}^{+}$currents (Atkinson et al., 1991; Tsunoda and Salkoff, 1995; Kim et al., 1998): BKKCa $\left(\mathrm{I}_{\mathrm{KCa}}\right)$, shaker $\left(\mathrm{I}_{\mathrm{A}}\right)$, and shab $\left(\mathrm{I}_{\mathrm{Kd}}\right)$. We detected a significant correlation between $B K K C a$ and shaker mRNA levels across a population of $20 \mathrm{LC}$ motor neurons (Fig. $2 A$, left), but no correlations among any other channel mRNAs (Fig. $2 \mathrm{~A}$, middle, right). A fourth channel mRNA encoding an A-type $\mathrm{K}^{+}$current, shal, also was significantly positively correlated to $\mathrm{BKKCa}$ mRNA levels $\left(p<0.005 ; R^{2}=0.58\right)$, as well as to shaker $(p<$ $\left.0.002 ; R^{2}=0.42\right)$ but not to shab, suggesting an overall relationship between $\mathrm{I}_{\mathrm{KCa}}$ and $\mathrm{I}_{\mathrm{A}}$, but not with $\mathrm{I}_{\mathrm{Kd}}$, in these cells.

We next examined the relationships among the ionic currents encoded by these channel genes across a population of LC motor neurons. $\mathrm{I}_{\mathrm{A}}, \mathrm{I}_{\mathrm{KCa}}$, and $\mathrm{I}_{\mathrm{Kd}}$ were all measured in each cell across a population of LC motor neurons. A similar pattern of correlated current levels was seen as with the mRNA with one striking distinction: only $\mathrm{I}_{\mathrm{A}}$ and $\mathrm{I}_{\mathrm{KCa}}$ showed a significant correlation (Fig. $2 \mathrm{~A}$ ), but the correlation was strongly negative as opposed to positive as seen in the mRNA measurements. No significant correlations were found between $\mathrm{I}_{\mathrm{A}}$ and $\mathrm{I}_{\mathrm{Kd}}$, or $\mathrm{I}_{\mathrm{KCa}}$ and $\mathrm{I}_{\mathrm{Kd}}$ (Fig. $2 \mathrm{~A}$ ). Because of the striking difference between the mRNA correlation (positive), and the current correlation (negative), we were most interested in pursuing the relationship between $\mathrm{I}_{\mathrm{A}}$ and $\mathrm{I}_{\mathrm{KCa}}$, but had concerns about the effects of pharmacological blockers used to measure $\mathrm{I}_{\mathrm{KCa}}$ (Fig. $3 \mathrm{~F}$ ); we use $\mathrm{Cd}^{2+}$ to block calcium currents that evoke $\mathrm{I}_{\mathrm{KCa}}$ to measure this current via subtraction from $\mathrm{I}_{\mathrm{HTK}}$, as we have not identified any blockers specific to $\mathrm{I}_{\mathrm{KCa}}$ in our preparation despite many attempts. Therefore, we decided to use the peak $\mathrm{I}_{\mathrm{HTK}}$ as an indicator of $\mathrm{I}_{\mathrm{KCa}}$ abundance in these experiments.

$\mathrm{I}_{\mathrm{HTK}}$ (HighThreshold $\mathrm{K}^{+}$) is known from previous work (Golowasch and Marder, 1992; Haedo and Golowasch, 2006; Khorkova and Golowasch, 2007) to, in large part, consist of $\mathrm{I}_{\mathrm{KCa}}$, particularly the transient portion, as $\mathrm{I}_{\mathrm{Kd}}$ shows no transient peak that could account for the peak in $\mathrm{I}_{\mathrm{HTK}}$ (Fig. $2 \mathrm{~B}$ ). We also determined that measurements of the peak $\mathrm{I}_{\mathrm{HTK}}$ were likely sufficient to reveal the relationship between $\mathrm{I}_{\mathrm{KCa}}$ and $\mathrm{I}_{\mathrm{A}}$, as the only transient peak seen in the currents that underlie $\mathrm{I}_{\mathrm{HTK}}$ belongs to $\mathrm{I}_{\mathrm{KCa}}$ (Fig. $2 \mathrm{~B}$, right). Peak $\mathrm{I}_{\mathrm{HTK}}$ also shows the same negative relationship with $\mathrm{I}_{\mathrm{A}}$ as does $\mathrm{I}_{\mathrm{KCa}}$ (Fig. $2 C$, left), and peak $\mathrm{I}_{\mathrm{KCa}}$ itself very strongly correlates with peak $\mathrm{I}_{\mathrm{HTK}}$ (Fig. $2 C$, middle), but not $\mathrm{I}_{\mathrm{Kd}}$ (Fig. 2C, right). Accordingly, for the remainder of the study, we 
used $\mathrm{I}_{\text {HTK }}$ peak current from baseline as a measure of $\mathrm{I}_{\mathrm{KCa}}$ abundance, to allow for measurement of all $\mathrm{K}^{+}$currents under the least manipulative pharmacological blocker regime, i.e., without the need to block voltage-gated calcium currents.

\section{$I_{\mathrm{KCa}}$ and $\mathrm{I}_{\mathrm{A}}$ are rapidly upregulated within the same LC motor neuron} Because the focus of the study was on the negative relationship between $\mathrm{I}_{\mathrm{A}}$ and $\mathrm{I}_{\mathrm{KCa}}$, we decided to repeat the initial measurements in a new population of LC motor neurons to confirm the original finding before examining the functional impact of this relationship. In a distinct population of 20 LC motor neurons, we once again found a strong negative relationship between $\mathrm{I}_{\mathrm{A}}$ and $\mathrm{I}_{\mathrm{KCa}}$ (as revealed by $\mathrm{I}_{\mathrm{HTK}}$ measurements; Fig. 3A), confirming our original finding. This strongly suggested a causal relationship between $\mathrm{I}_{\mathrm{A}}$ and $\mathrm{I}_{\mathrm{KCa}}$. Specifically, we hypothesized that if these two currents are functionally interrelated, then a decreased level of $\mathrm{I}_{\mathrm{A}}$ should result in an increased level of $\mathrm{I}_{\mathrm{KCa}}$ and vice versa. We tested this hypothesis by blocking one current in this pair and determining whether there was an effect on the magnitude of the other. We measured baseline levels of $\mathrm{I}_{\mathrm{A}}$ in a given cell, then used tetraethylammonium (TEA) to block the HTK-current for $60 \mathrm{~min}$, and then measured $\mathrm{I}_{\mathrm{A}}$ again post-TEA. $60 \mathrm{~min}$ of exposure to TEA significantly increased peak $(p<0.001$; paired $t$ test) A-current (Fig. $3 B, C)$. The converse experiment was performed using 4-aminopyridine (4AP) for 60 min to block $\mathrm{I}_{\mathrm{A}}$. The peak $(p<0.003)$ of $\mathrm{I}_{\mathrm{HTK}}$ was significantly increased following $60 \mathrm{~min}$ of 4 -AP blockade (Fig. 3 B, C). Additionally, these results appear to be due to an overall increase in conductance, since no change was seen in the voltages of activation of $\mathrm{I}_{\mathrm{A}}$ and $\mathrm{I}_{\mathrm{HTK}}$ concomitant with the changes in total current as a result of the block experiments (Fig. $3 D$ ). No consistent or significant effects of TEA and 4-AP on neuronal input resistance were observed in these cells $\left(\Delta \mathrm{R}_{\mathrm{IN}} \mathrm{TEA}:-1.87 \pm 2.5 \mathrm{M} \Omega, \Delta \mathrm{R}_{\mathrm{IN}}\right.$ 4-AP: $-0.52 \pm 1.7 \mathrm{M} \Omega$ ).

Our initial data strongly implicate $\mathrm{I}_{\mathrm{KCa}}$ and $\mathrm{I}_{\mathrm{A}}$ as the key pair of currents involved in this response. Since $\mathrm{I}_{\mathrm{HTK}}$ is a mixed current comprised predominantly of $\mathrm{I}_{\mathrm{KCa}}$ and $\mathrm{I}_{\mathrm{Kd}}$, and both of these currents are blocked by TEA, we determined whether the changes seen in $\mathrm{I}_{\mathrm{HTK}}$ as a result of $4 \mathrm{AP}$ blockade were attributable to just one or to both of these currents. Most convincingly, while 4AP block significantly increases $\mathrm{I}_{\mathrm{HTK}}$ (Fig. $3 C$ ), $1 \mathrm{~h}$ of exposure to 4AP had no significant effect on $\mathrm{I}_{\mathrm{Kd}}$ magnitude itself (Fig. $3 E$, left). Unfortunately, we have not identified a blocker specific to $\mathrm{I}_{\mathrm{KCa}}$ in our preparation to directly test the effects of blocking this current on changes in $\mathrm{I}_{\mathrm{A}}$. However, we can indirectly block $\mathrm{I}_{\mathrm{KCa}}$ by using $\mathrm{CdCl}_{2}$ to block voltage-gated $\mathrm{Ca}^{2+}$ channels that trigger $\mathrm{I}_{\mathrm{KCa}}$. Blocking with $\mathrm{Cd}^{2+}$ completely eliminates $\mathrm{I}_{\mathrm{KCa}}$ in these cells, and causes a significant increase in $\mathrm{I}_{\mathrm{A}}$ after $1 \mathrm{~h}$ of exposure that is very similar to that seen with TEA (Fig. 3E, right). Together, these data strongly suggest that the relationship between
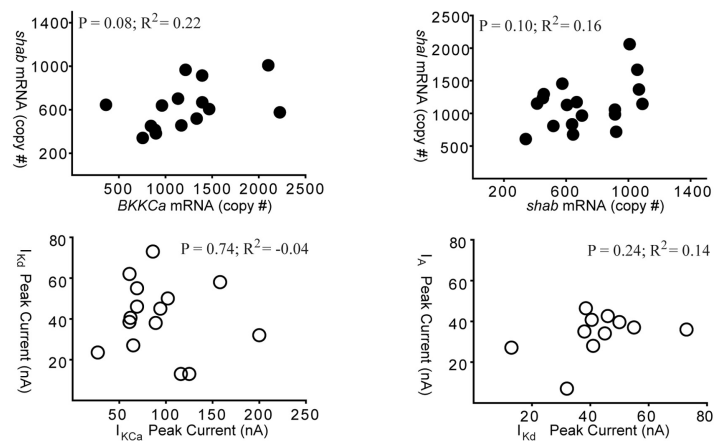

I
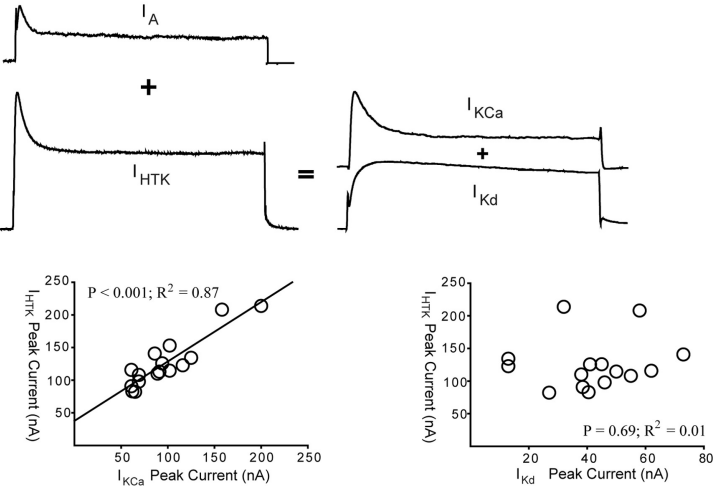

Figure 2. Relationships among channel gene mRNA levels and among ionic currents in a normal population of large cell motor neurons. $\boldsymbol{A}$, Correlations between mRNA levels from single identified LC motor neurons for BKKC $a$, shaker, and shab channel genes

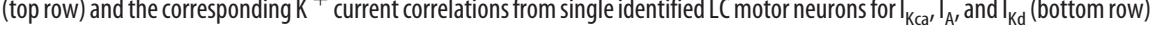
of statistics refers to the entire dataset, while the dotted line and the bottom set of statistics represents the correlation with the single point indicated by the arrow removed. Despite having this outlier removed, the correlation is still significant and largely $\mathrm{I}_{\mathrm{HTK}}$ peak levels as an indicator of $\mathrm{I}_{\mathrm{KCa}}$ for any given cell for the remainder of the study. Statistics as in $\boldsymbol{A}$.

$\mathrm{I}_{\mathrm{A}}$ and $\mathrm{I}_{\mathrm{HTK}}$ identified in the experiments (Fig. 3) are the result of a causal relationship between the levels of $\mathrm{I}_{\mathrm{A}}$ and $\mathrm{I}_{\mathrm{KCa}}$ in a given motor neuron.

\section{$I_{A}$ and $I_{K C a}$ act in a compensatory fashion to stabilize cellular} excitability and network output

The negative correlation we measured between $\mathrm{I}_{\mathrm{A}}$ and $\mathrm{I}_{\mathrm{KCa}}$ in the normal population, together with the rapid change in currents seen within a cell after TEA and 4AP block, led us to hypothesize that levels of $\mathrm{I}_{\mathrm{A}}$ and $\mathrm{I}_{\mathrm{KCa}}$ may be acting in a compensatory fashion to stabilize both cellular and network output. To determine whether such a functional compensation exists, we followed over time the activity of both isolated LCs, as well as LCs in an intact network, with either 4AP or TEA blockade, and then determined whether the output of the cells and of the network changed over the course of the blockade and the potential compensation.

As seen in Figure 4, $A$ and $B$, TEA blockade caused a substantial increase in the excitability of the LC motor neuron in the initial 10-20 min. However, over the time course of the measured increase in $\mathrm{I}_{\mathrm{A}}$ seen in previous experiments (Fig. 2C) there was a compensatory change in the output of the cell and of the network toward the baseline level of activity. In isolated LCs (Fig. 4A), both TEA and 4AP application shifted the cells from a less excitable state to a state characterized by large sustained burst potentials. However, over the time course of compensation, the 

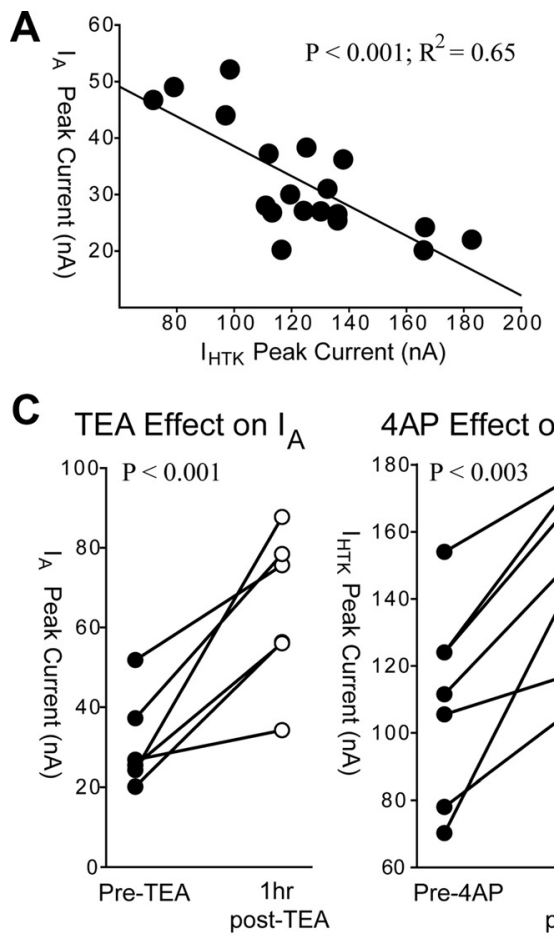

B

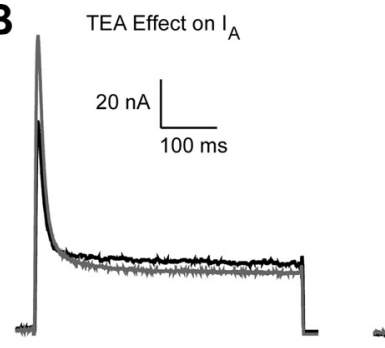

D TEA Effect on IA

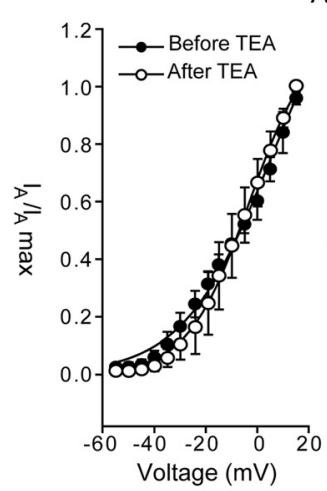

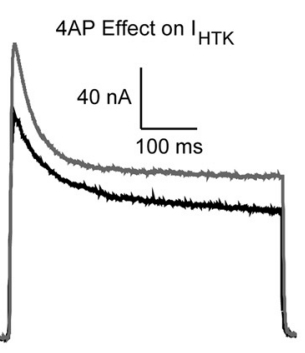

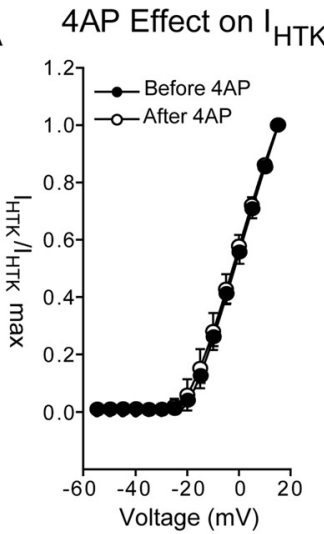

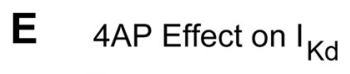
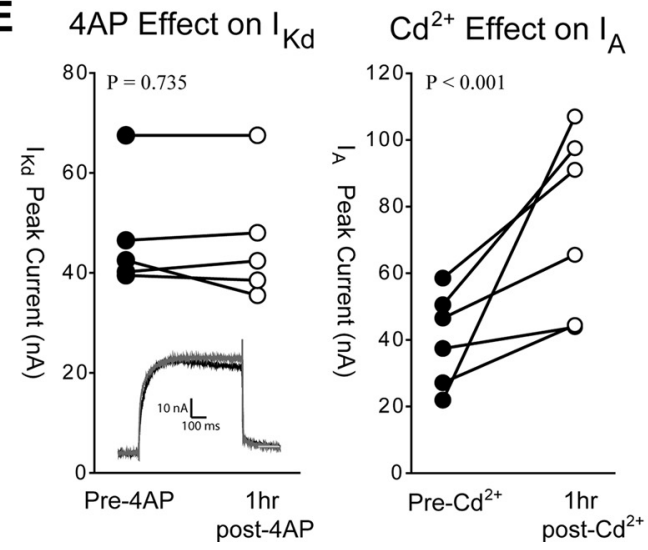

Figure 3. Reciprocal interaction of $\mathrm{I}_{A}$ and $\mathrm{I}_{\text {HTK }}$ levels in $\mathrm{LC}$ motor neurons. $A$, Correlation between peak $\mathrm{I}_{A}$ and $\mathrm{I}_{\text {HTK }}$ across a second population of $\mathrm{LC}$ motor neurons distinct from those in Figure 2 . Statistics represent results of a Pearson's test $(n=20)$. $B$, Representative recordings of the increase in $I_{A}$ after TEA exposure (left) and the increase in $I_{H T K}$ after $4 A$ P exposure (right). Black trace is the control, gray trace is the same cell after 60 min exposure to blocker. C, Quantified effects of TEA (left) and 4AP (right) on the peak $I_{A}$ and $I_{\text {HTK }}$ respectively in $N=6$ cells. The same cell before (black) and after (white) is connected with a solid line. Statistics represent paired $t$ test on mean current before and after blocker. $D$, Activation characteristics, expressed as $I / I_{\max }$ for an $N=5$ cells, of $I_{A}$ (left) and $I_{H T K}$ (right) before and after block with TEA and 4AP, respectively. Each point represents mean $\pm S D$. $E$, Effects of $4 A P$ on $I_{K d}(l e f t ; N=5)$ and $\left(d^{2+}\right.$ on $I_{A}($ right; $N=6)$. Insert in the left panel shows representative traces of $\mathrm{I}_{\mathrm{Kd}}$ before (black) and after (gray) exposure to 4AP. Legends and statistics as in $\boldsymbol{C}$.

excitability of isolated cells returned to control levels, losing the large burst potentials and showing firing patterns similar to those before the application of the blocker (Fig. $4 A$ ).

In the intact network, TEA often caused a complex multiphase bursting output in treated LCs (Fig. $4 B ; 10$ min recording). Given this somewhat complex pattern of bursting, we determined that measurements of burst duration across a population of these cells represented the clearest means to quantify changes in output over time. Over the course of 60-90 min, TEA blockade resulted in a significant change in burst duration $(p<0.01$; ANOVA; Fig. $4 C$, left), initially increasing to nearly twice as long as control before re-establishing a stable burst duration indistinguishable from that at the control level (Fig. 4B).

In the companion experiment with $4 \mathrm{AP}$ blockade in the intact network, we see a similar effect of compensation as in the LC motor neuron output (seen in Fig. $4 B, C$ ). 4 AP block does not cause the same change in burst duration as with TEA. Rather, $4 \mathrm{AP}$ blockade initially causes a significant increase in spike frequency and the number of spikes fired per burst $(p<0.01$; ANOVA). Over the time course of the blockade, this spike frequency and number of spikes per burst returns to control levels (Fig. $4 D$ ). These data indicate that the changes seen in the level of $\mathrm{I}_{\mathrm{A}}$ and $\mathrm{I}_{\mathrm{KCa}}$ as a result of TEA and 4AP block, respectively, are a functional compensatory response that stabilizes the output of the cells and of the network as a whole. However, the roles of $\mathrm{I}_{\mathrm{A}}$ and $\mathrm{I}_{\mathrm{KCa}}$ are not simply functionally redundant; blocking either current causes an initial change in the output of the cell that is not the same. These results implicate distinct roles for these two currents in addition to their ability to partially compensate for one another. However, we do not rule out the possibility that there could be other currents or mechanisms involved in the compensatory effect. 
Compensatory changes in $\mathrm{I}_{\mathrm{A}}$ and $\mathrm{I}_{\mathrm{KCa}}$ follow distinct regulatory pathways We then set out to determine the underlying mechanisms implementing the compensation in these currents. We first investigated whether the change in $\mathrm{I}_{\mathrm{KCa}}$ elicited by $4 \mathrm{AP}$ blockade was dependent on intracellular calcium. To check this, we coapplied the calcium chelator BAPTA with the blocker. When BAPTA was co-applied with $4 \mathrm{AP}$, there was no change in $\mathrm{I}_{\mathrm{HTK}}$, in contrast to the characteristically significant increase in $\mathrm{I}_{\mathrm{HTK}}$ with 4AP blockade (Fig. $5 A)$. We also confirmed that this effect was not simply due to an effect of BAPTA on the calcium-dependence of $\mathrm{I}_{\mathrm{KCa}}$; BAPTA alone did not result in a significant reduction of $\mathrm{I}_{\mathrm{HTK}}$ (data not shown; see also Turrigiano et al., 1994). More specifically, the calcium dependence of the increase in $\mathrm{I}_{\mathrm{HTK}}$ was attributable to the release from intracellular calcium stores since co-application of 4AP and the intracellular calcium release blocker ryanodine also prevented the compensatory increase in $\mathrm{I}_{\mathrm{HTK}}$ normally seen with 4AP blockade (Fig. 5A). These results suggest that the compensatory increase in $\mathrm{I}_{\mathrm{KCa}}$ is dependent on intracellular calcium signaling mechanisms that depend on the release of intracellular calcium stores.

Because relatively rapid changes in current magnitude can often be attributed to changes in phosphorylation states of ion channels and associated regulatory proteins, we examined the effects of phosphatase and kinase inhibitors on the ability of the blockers to elicit the compensatory changes in these currents. Okadaic acid is a broad spectrum inhibitor of serine/threonine protein phosphatases (Cohen et al., 1990). While application of okadaic acid alone did not affect baseline levels of $\mathrm{I}_{\mathrm{HTK}}$ (data not shown), co-application of okadaic acid with 4AP also abolished the compensatory increase in $\mathrm{I}_{\mathrm{HTK}}$ (Fig. $5 A$ ), suggesting the action of a serine/threonine protein phosphatase in this compensatory effect. Because calcineurin is a well known $\mathrm{Ca}^{2+}$-dependent protein serine/ threonine phosphatase (Klee et al., 1998), we used cyclosporine A to inhibit calcineurin activity in our system. Cyclosporine alone did not affect baseline levels of $\mathrm{I}_{\mathrm{HTK}}$ (data not shown), but combined application of $4 \mathrm{AP}$ with cyclosporine eliminated the compensatory increase in $\mathrm{I}_{\mathrm{HTK}}$ (Fig. 5A), indicating that the increase in $\mathrm{I}_{\mathrm{HTK}}$ is dependent, at least in part, on the activity of calcineurin.

In complete contrast, the compensatory influence of TEA on $\mathrm{I}_{\mathrm{A}}$ appears to be implemented via mechanistically distinct pathways compared with those we found for the $4 \mathrm{AP}$ block on $\mathrm{I}_{\mathrm{HTK}}$. The increase of $\mathrm{I}_{\mathrm{A}}$ in response to TEA blockade is neither calcium-dependent (Fig. 5B) nor dependent on the activity of serine/threonine phosphatases (Fig. 5B). Parallel experiments showed that BAPTA, ryanodine, okadaic acid and cyclosporine,

B
TEA block
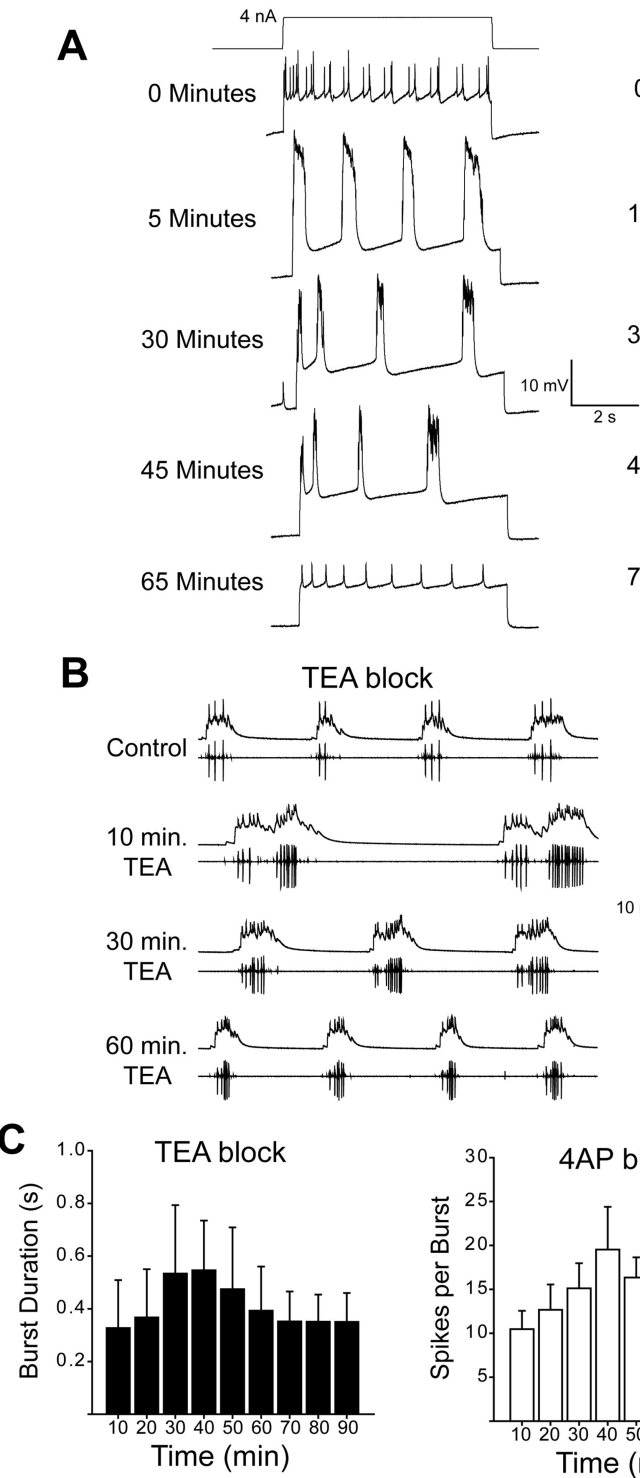

Figure 4. $\mathrm{I}_{\mathrm{A}}$ and $\mathrm{I}_{\mathrm{KCa}}$ engage in a compensatory relationship that stabilizes neuronal excitability and network output. $\boldsymbol{A}$ Representative recordings of the effects on the excitability of individual $\mathrm{LC}$ motor neurons isolated from network activity after exposure to TEA (left) and 4AP (right). Because the pacemaker neurons of the network were silenced with TTX in this experiment, $D C$ current injections were used to elicit activity in LC motor neurons (current traces shown at top). $\boldsymbol{B}$, Representative recordings of the effects of TEA (left) and 4AP (right) exposure on network output over time. Pacemaker cells were shielded from exposure to the of $L C$ motor neurons in the intact network. Bars represent mean \pm SD of $N=5$ preparations at 10 min intervals. The first 10 min interval is baseline without blocker, and subsequent bins represent cumulative time after blocker exposure.

when co-applied with TEA, failed to prevent a significant increase in $\mathrm{I}_{\mathrm{A}}$ (Fig. $5 B$ ). The only exception was that the application of ryanodine in conjunction with TEA appeared to reduce the magnitude of increase in $\mathrm{I}_{\mathrm{A}}$, although this effect was not statistically significant with respect to TEA alone ( $p=0.103$; $t$ test), or TEA plus BAPTA $(p=0.08)$.

We also examined the effects of inhibiting kinase activity on the compensatory effects of $4 \mathrm{AP}$ and TEA blockade. Staurosporine is a potent, cell-permeable protein kinase $\mathrm{C}$ inhibitor which also partially inhibits other kinases such as PKA, PKG, and CaMKII (Rüegg and Burgess, 1989). Co-application of staurosporine with $4 \mathrm{AP}$ appears to cause a significant decrease in $\mathrm{I}_{\mathrm{HTK}}$ (Fig. $5 \mathrm{~A}$ ). 


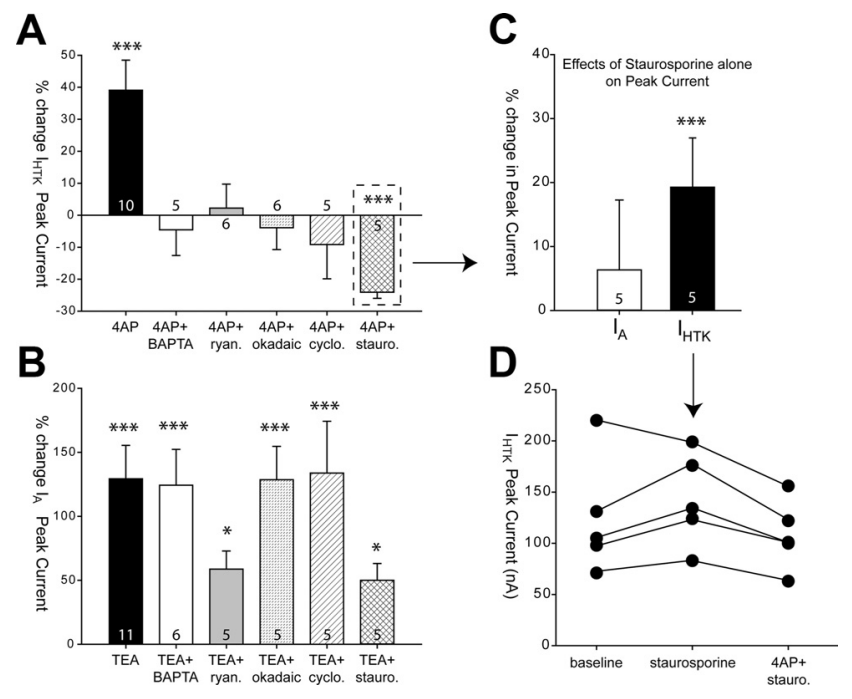

Figure 5. Use of pharmacological inhibitors to probe mechanisms of changes in $\mathrm{I}_{\mathrm{A}}$ and $\mathrm{I}_{\mathrm{KCa}}$. $\boldsymbol{A}$, Effects of BAPTA, ryanodine, okadaic acid, cyclosporine, and staurosporine (referred to as the treatment) on the induction of increased $I_{\text {HTK }}$ with 4AP exposure. All bars are mean $\pm S D$, sample sizes as shown in bars. All results are percentage change in peak $I_{\text {HTK }}$ with 4AP + treatment relative to treatment alone (see Materials and Methods). None of the treatments caused a change in baseline levels of $\mathrm{I}_{\text {HTK }}$ with the exception of staurosporine (dotted box; see C). ${ }^{* * *}$ represents a significant $(p<0.001$ ) difference from 0 via one-sample $t$ test. $\boldsymbol{B}$, Effects of BAPTA, ryanodine, okadaic acid, cyclosporine, and staurosporine on the induction of increased $\mathrm{I}_{A}$ with TEA exposure. All results are percentage change in peak $\mathrm{I}_{A}$ with TEA + treatment relative to treatment alone (see Materials and Methods). None of the treatments caused a change in baseline levels of $\mathrm{I}_{\mathrm{A}} \cdot{ }^{* * *} p<0.001$ and ${ }^{*} p<0.01$ represent a significant difference from 0 via one-sample $t$ test. $C$, Effects of staurosporine alone on baseline levels of $\mathrm{I}_{A}$ and $\mathrm{I}_{\text {HTK }}$. ${ }^{* *}$ represents a significant $(p<0.001)$ difference from 0 via one-sample $t$ test. $D, 0$ verall effects of staurosporine alone and then $4 \mathrm{AP}+$ staurosporine on $\mathrm{I}_{\mathrm{HTK}}$. Each individual cell is connected with a solid line across the treatments.

However, this is a more complex result than that for the other pharmacological blockers. Unlike any of the other pharmacological blockers used in this study, staurosporine was the only one to cause a change in baseline levels of $\mathrm{I}_{\mathrm{HTK}}$ when applied alone (Fig. $5 C)$. Therefore, combined application of $4 \mathrm{AP}$ and staurosporine results in a relative decrease in $\mathrm{I}_{\mathrm{HTK}}$ compared to that with staurosporine alone, but the net effect of $4 \mathrm{AP}+$ staurosporine is a restoration of $\mathrm{I}_{\mathrm{HTK}}$ to baseline levels (Fig. 5D).

Once again, the effects of staurosporine on $\mathrm{I}_{\mathrm{A}}$ in the context of TEA blockade contrast with those for $4 \mathrm{AP}$ and $\mathrm{I}_{\mathrm{HTK}}$. There is no effect of staurosporine on baseline levels of $\mathrm{I}_{\mathrm{A}}$ (Fig. 5C), and while staurosporine co-applied with TEA results in an apparent decrease in the magnitude of the effect on $\mathrm{I}_{A}$, there is still a significant increase in $\mathrm{I}_{\mathrm{A}}$ with staurosporine present (Fig. $5 B$ ), which is not statistically significant from the effect of TEA alone $(p=0.08$; $t$ test).

\section{Discussion}

Rapid compensation between $\mathrm{I}_{\mathrm{A}}$ and $\mathrm{I}_{\mathrm{KCa}}$ preserves both cellular and network outputs

We have identified a naturally occurring coregulatory relationship between potassium currents $\left(\mathrm{I}_{\mathrm{A}}\right.$ and $\left.\mathrm{I}_{\mathrm{KCa}}\right)$ in an intact $\mathrm{CPG}$ network that results in homeostatic compensation of neuronal excitability as well as network function. Furthermore, we have determined that these compensatory changes in $\mathrm{K}^{+}$current magnitudes are independently regulated by distinct mechanisms. Compensatory increases in $\mathrm{I}_{\mathrm{KCa}}$ are calcium-dependent and due, at least in part, to the activity of calcineurin-based phosphatase activity. Conversely, compensatory increases in $\mathrm{I}_{\mathrm{A}}$ are indepen- dent of all of the regulatory pathways implicated in the $\mathrm{I}_{\mathrm{KCa}}$ response. These effects are also fairly rapid, acting over the course of 60-90 min to stabilize the activity of a critical CPG network responsible for cardiac muscle contraction and heart beat generation in the animal. While such homeostatic responses and their role in stabilizing synaptic function have been well studied (Bergquist et al., 2010; Turrigiano, 2011), we know much less about the mechanisms underlying homeostatic plasticity of intrinsic excitability and the role this form of plasticity plays in the stabilization of neuronal and motor network output (Turrigiano, 2011).

Even neurons and networks with extremely robust output display highly variable underlying physiological parameters responsible for neuronal output, particularly membrane conductances (Schulz et al., 2006a, 2007; Khorkova and Golowasch, 2007; Goaillard et al., 2009; Temporal et al., 2012). Our work reveals that embedded within this variability are coregulatory relationships that act to stabilize the excitability of the cell, in part by balancing the sum total of major transient outward currents, $\mathrm{I}_{\mathrm{A}}$ and $\mathrm{I}_{\mathrm{KCa}}$. A similar relationship between $\mathrm{I}_{\mathrm{A}}$ and $\mathrm{I}_{\mathrm{KCa}}$ was reported in the STG. Artificial depolarization of inferior cardiac neurons results in increased $\mathrm{I}_{\mathrm{A}}$ and decreased $\mathrm{I}_{\mathrm{HTK}}$, which is abolished by $\mathrm{Cd}^{2+}$ blockade of calcium channels (Golowasch et al., 1999). These experiments did not reveal a naturally existing correlation between these currents (Golowasch et al., 1999), suggesting that excitability in the STG may be a more complex interaction among multiple conductances, or perhaps between conductances and their constitutive neuromodulation (HarrisWarrick, 2011). Although it is not known what effect this has on network output in the STG, our complementary results suggest that such homeostatic mechanisms may be common among motor neurons in different CPGs.

\section{Distinct intracellular pathways mediate compensation}

The mechanisms involved in the regulation of the compensatory response mediated by $\mathrm{I}_{\mathrm{KCa}}$ after $4 \mathrm{AP}$ block in the CG network are consistent with work supporting changes in $\mathrm{K}^{+}$current density in a homeostatic fashion (Desai et al., 1999; Schulz et al., 2006b; Debanne and Poo, 2010; Misonou, 2010). In particular, the mechanisms we see for the compensatory increase in $\mathrm{I}_{\mathrm{KCa}}$ are similar to those found in regulation of excitability in cultured hippocampal neurons (Misonou et al., 2004, 2005; Misonou and Trimmer, 2004). Increased excitability in these cultured neurons results in calcineurin-dependent dephosphorylation of Kv2.1 channels, leading to a functional potentiation of these channels via a shift in activation voltage, and to restoration of excitability (Misonou et al., 2004). While our data strongly suggest that $\mathrm{I}_{\mathrm{KCa}}$ is primarily responsible for the observed change in $\mathrm{I}_{\mathrm{HTK}}$, we cannot conclusively rule out a role for $\mathrm{I}_{\mathrm{Kd}}$ (similar to Kv2.1). However, cyclosporine has been shown to alter $\mathrm{I}_{\mathrm{KCa}}$ channels directly (Hay, 1998), and calcineurin is known to have widespread effects on neuronal plasticity and excitability beyond its effects on Kv2.1 activity (Groth et al., 2003). The effects seen in our experiments likely can be attributed to an overall increase in the maximal conductance of $\mathrm{I}_{\mathrm{KCa}}$, as we see no changes in either activation curves or any consistent or significant changes in input resistances of these cells (O'Leary et al., 2010).

The mechanisms underlying compensatory increases in $\mathrm{I}_{\mathrm{A}}$ are less clear, but distinct from the pathways involved in the upregulation of $\mathrm{I}_{\mathrm{KCa}}$. Unlike for $\mathrm{I}_{\mathrm{KCa}}$, the increase in $\mathrm{I}_{\mathrm{A}}$ is neither calcium-dependent, nor influenced by the activity of calcineurin or any other phosphatases that would be affected by treatment with okadaic acid (Cohen et al., 1990). Indeed, blocking neither 


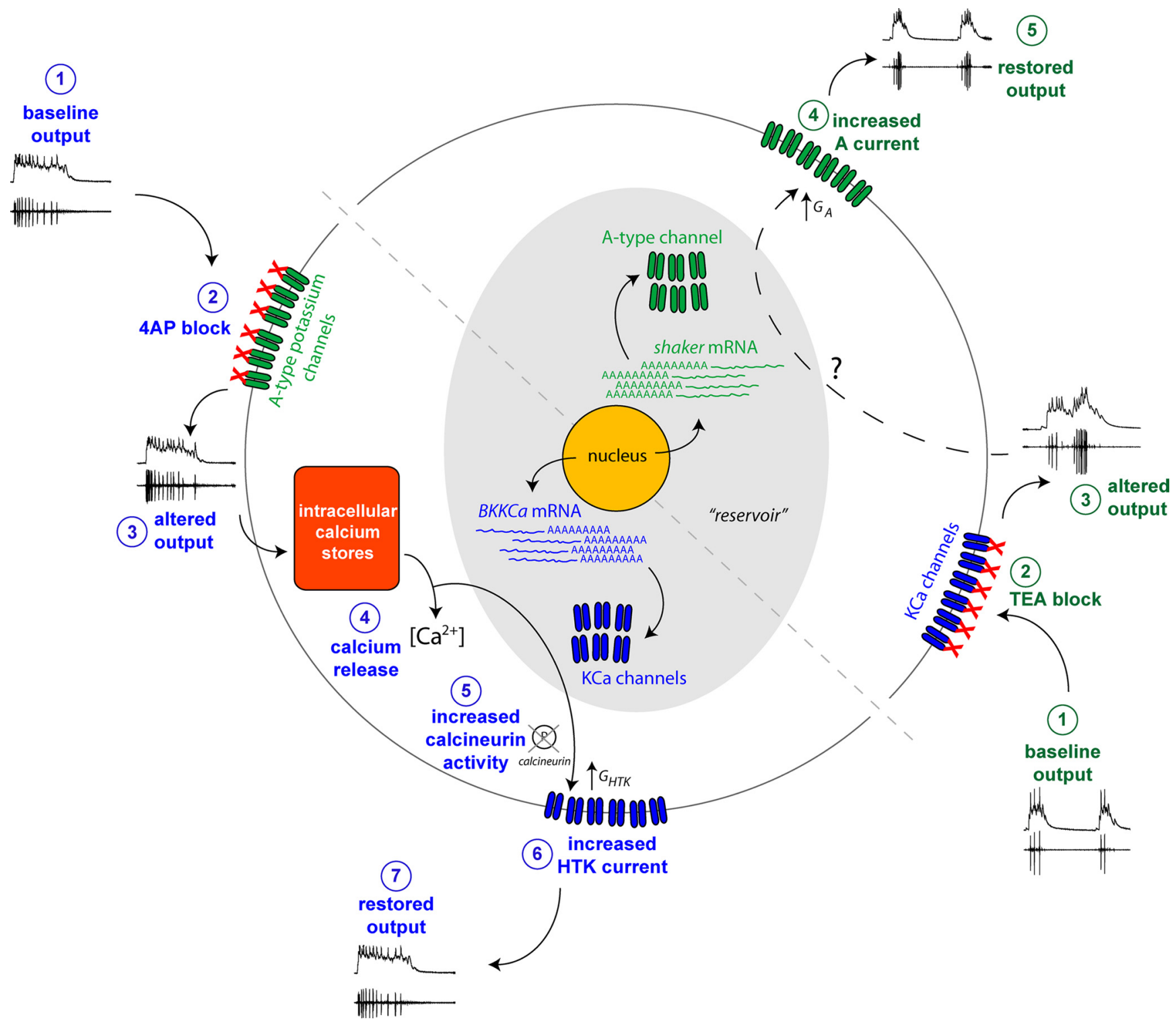

Figure 6. A working model for the induction of homeostatic plasticity of intrinsic excitability via rapid compensation between $\mathrm{I}_{\mathrm{A}}$ and $\mathrm{I}_{\mathrm{KCa}}$. This model summarizes all of the data in the current study and provides a framework for interpretation and future experimentation. The two halves of the cell represent the distinct mechanisms induced by a block of $\mathrm{I}_{A}$ with $4 A P$ (left, blue pathway) and a block of $\mathrm{KCa}_{\text {a }}$ with TEA (right, green pathway). Blue Pathway (4AP blockade): The baseline activity (1) is disrupted by the block of A-type channels with 4AP (2), causing an alteration in the excitability of the cell and its output in the network, in this case rapid initial firing frequency (3). This change presumably results in the release of calcium from intracellular stores (4) that increases activity of the calcium-dependent phosphatase calcineurin (5). Calcineurin activity induces an increase in $\mathrm{K}_{\mathrm{KCa}}(6)$, restoring the excitability of the cell and re-establishing motor neuron activity in the intact network (7). Green Pathway (TEA blockade): Baseline network activity (1) is disrupted via TEA blockade (2), causing substantial changes in the output properties of the motor neuron and the network (3). While the intracellular mechanisms remain unclear at this point, a subsequent increase in $I_{A}$ that is independent of the pathway invoked by $4 A$ P blockade compensates for loss of $I_{K C a}$ restoring output of the neurons and the network (5). This compensation is rapid (on the order of $1 \mathrm{~h}$ ), suggesting that there is an already existing "reservoir" or channel protein available that is maintained via positive coregulation at the transcription/mRNA level of the channel genes responsible for $\mathrm{I}_{\mathrm{KCa}}$ and $\mathrm{I}_{\mathrm{A}}$ (Gray Oval).

phosphatase nor kinase activity by two broad spectrum blockers was able to prevent an increase in $\mathrm{I}_{\mathrm{A}}$ as a result of TEA blockade, possibly precluding the contribution of phosphorylation state to this half of the compensation story. However, we were able to dampen the effect by blocking release of intracellular calcium with ryanodine, as well as by inhibiting kinase activity, suggesting a more complex path of regulation in this response. Given the potential nonspecific effects of pharmacological treatment, we cannot rule out at least some role for a kinase in this pathway. For example, Kv1.2 potassium channels are known to be affected by cAMP/protein kinase A pathways which enhance their conductance, in part by altering trafficking of these channels (Connors et al., 2008). Our staurosporine treatment may result in only partial inhibition of PKA (Rüegg and Burgess, 1989), which could explain the intermediate effects seen on the A-type current compensation. Regardless, the fact that $\mathrm{I}_{\mathrm{A}}$ and $\mathrm{I}_{\mathrm{KCa}}$ are regulated by distinct pathways demonstrates an inherent robustness to this homeostatic response, which may be characteristic of networks responsible for critical functions, such as CPGs.

\section{Reservoirs of channel proteins might implement rapid compensation}

Our data also begin to shed light on a striking disparity between levels of regulation in this system. Namely, we see an entirely different relationship at the level of mRNA for the channel genes $B K K C A$ and shaker (positive correlation), than we do for the 
currents $\mathrm{I}_{\mathrm{KCa}}$ and $\mathrm{I}_{\mathrm{A}}$ that these channels most directly encode (negative correlation). Indeed, to date every correlation we have found between channel mRNAs at the single cell level has been a positive correlation (Schulz et al., 2007; Tobin et al., 2009; Temporal et al., 2012). These data include measurements of at least nine different channel genes in seven different motor neuron types in the crustacean stomatogastric and cardiac ganglia (S. Temporal and D. J. Schulz, unpublished data), for a total of no fewer than 60 correlations in channel expression detected among channel transcript levels, and every one has thus far been positive. In addition, our data impact the present, although admittedly limited, understanding of the relationship between channel mRNA and ionic current in a given neuron. Namely, that mRNA for a given $\mathrm{K}^{+}$channel correlates positively with its corresponding ionic conductance (Schulz et al., 2006). Although both of these measurements were not made in the same cells in this study, logic dictates that there cannot simply be a positive relationship between mRNA and conductance for both $\mathrm{K}^{+}$currents in this study. Clearly, and not particularly surprisingly, our data demonstrate that more complexity lies within the relationship of mRNA and ionic conductance than a one-for-one tracking between these disparate levels of function in all cell types. However, our data continue to support the concept that correlation among mRNA levels (Schulz et al., 2007; Tobin et al., 2009) underlies a functional relationship at the conductance level.

So then why do we see only positively correlated mRNA levels for channel genes in these motor networks? The linkage to cellular and network output in our study enables us to propose a new hypothesis in this regard. We hypothesize that rapid compensation of intrinsic excitability, such as that reported in this study, is implemented via an already existing pool of protein. That is, protein pools for the two opposing channels must already be available in relatively equivalent numbers, even if they are not functionally equally represented. This requires that mechanisms must occur at the level of gene regulation to ensure a sufficient "reservoir" of protein capable of compensating for the loss of a given channel. Thus, regardless of whether channels act in concert to set neuronal output (Ball et al., 2010; Franklin et al., 2010), or act in a compensatory fashion, the overall gene regulation between the two must be relatively balanced. Such a reservoir perspective is reminiscent of mechanisms seen for synaptic vesicle protein dynamics (Fernández-Alfonso et al., 2006), or extrasynaptic AMPA receptors that serve as a reservoir during synaptic plasticity (Hayashi et al., 2000; Zhu et al., 2000). Interestingly, insertion of AMPA receptor during synaptic plasticity is also under the control of phosphorylation-dependent processes (Lin et al., 2009). Therefore, this hypothesis provides a compelling framework for future investigation of the relationship between mRNA levels and ionic conductance, as well as the interplay between gene expression and post-transcriptional mechanisms involved in homeostatic plasticity of intrinsic excitability over different time scales.

\section{Putting it all together}

Our findings represent one of the first comprehensive demonstrations of rapid homeostatic plasticity of intrinsic excitability that results in a stabilization of output in a mature, intact network of a CPG. These rapid compensatory increases are mechanistically independent, suggesting robustness in the maintenance of neural network output that is critical for survival. Furthermore, this study reveals a distinct mechanism for compensation that leads us to at least one working model of homeostatic plasticity in this system (Fig. 6). We hypothesize that one pathway to func- tional compensation in this system relies on intracellular calcium concentration as a measure of cell excitability (Kennedy, 1989; Ross, 1989; LeMasson et al., 1993). A block of A-type $\mathrm{K}^{+}$channels leads to an increase in the excitability of the cell, causing release of intracellular calcium stores. This calcium influx alters calcineurin activity, resulting in dephosphorylation of targets, perhaps the KCa-channels themselves, that increases $\mathrm{I}_{\mathrm{KCa}}$. This ultimately restores the outward current balance that was lost during decreased $\mathrm{I}_{\mathrm{A}}$ and thus restores excitability. The corresponding mechanism responsible for compensatory increases in $\mathrm{I}_{\mathrm{A}}$ (Fig. 6) is presently unknown, but is likely to involve distinct mechanisms for monitoring excitability (Dirnagl et al., 2003), as well as other candidate mechanisms that alter A-type conductances (Connors et al., 2008). Finally, we hypothesize that positive coregulation of mRNA numbers for channel genes may ultimately provide a reservoir of channel protein (Fig. 6) for implementing compensation over rapid time scales during which de novo synthesis may be insufficient to implement full compensation.

\section{References}

Alexandrowicz JS (1932) The innervation of the heart of the crusacea. I. Decapoda. Q J Microsc Sci 75:181-249.

Atkinson NS, Robertson GA, Ganetzky B (1991) A component of calciumactivated potassium channels encoded by the Drosophila slo locus. Science 253:551-555.

Ball JM, Franklin CC, Tobin AE, Schulz DJ, Nair SS (2010) Coregulation of ion channel conductances preserves output in a computational model of a crustacean cardiac motor neuron. J Neurosci 30:8637-8649.

Bergquist S, Dickman DK, Davis GW (2010) A hierarchy of cell intrinsic and target-derived homeostatic signaling. Neuron 66:220-234.

Berlind JA (1989) Feedback from motor neurones to pacemaker neurones in lobster cardiac ganglion contributes to regulation of burst frequency. J Exp Biol 141:277-294.

Cohen P, Holmes CF, Tsukitani Y (1990) Okadaic acid: a new probe for the study of cellular regulation. Trends Biochem Sci 15:98-102.

Connors EC, Ballif BA, Morielli AD (2008) Homeostatic regulation of Kv1.2 potassium channel trafficking by cyclic AMP. J Biol Chem 283:3445-3453.

Cooke IM (2002) Reliable, responsive pacemaking and pattern generation with minimal cell numbers: the crustacean cardiac ganglion. Biol Bull 202:108-136.

Debanne D, Poo MM (2010) Spike-timing dependent plasticity beyond synapse-pre- and post-synaptic plasticity of intrinsic neuronal excitability. Front Synaptic Neurosci 2:21.

Desai NS, Rutherford LC, Turrigiano GG (1999) Plasticity in the intrinsic excitability of cortical pyramidal neurons. Nat Neurosci 2:515-520.

Dirnagl U, Simon RP, Hallenbeck JM (2003) Ischemic tolerance and endogenous neuroprotection. Trends Neurosci 26:248-254.

Fernández-Alfonso T, Kwan R, Ryan TA (2006) Synaptic vesicles interchange their membrane proteins with a large surface reservoir during recycling. Neuron 51:179-186.

Franklin CC, Ball JM, Schulz DJ, Nair SS (2010) Generation and preservation of the slow underlying membrane potential oscillation in model bursting neurons. J Neurophysiol 104:1589-1602.

García-Crescioni K, Fort TJ, Stern E, Brezina V, Miller MW (2010) Feedback from peripheral musculature to central pattern generator in the neurogenic heart of the crab Callinectes sapidus: role of mechanosensitive dendrites. J Neurophysiol 103:83-96.

Goaillard JM, Taylor AL, Schulz DJ, Marder E (2009) Functional consequences of animal-to-animal variation in circuit parameters. Nat Neurosci 12:1424-1430.

Golowasch J, Marder E (1992) Ionic currents of the lateral pyloric neuron of the stomatogastric ganglion of the crab. J Neurophysiol 67:318-331.

Golowasch J, Abbott LF, Marder E (1999) Activity-dependent regulation of potassium currents in an identified neuron of the stomatogastric ganglion of the crab Cancer borealis. J Neurosci 19:RC33.

Groth RD, Dunbar RL, Mermelstein PG (2003) Calcineurin regulation of neuronal plasticity. Biochem Biophys Res Commun 311:1159-1171.

Guo W, Jung WE, Marionneau C, Aimond F, Xu H, Yamada KA, Schwarz TL, Demolombe S, Nerbonne JM (2005) Targeted deletion of Kv4.2 elimi- 
nates I(to,f) and results in electrical and molecular remodeling, with no evidence of ventricular hypertrophy or myocardial dysfunction. Circ Res 97:1342-1350.

Haedo RJ, Golowasch J (2006) Ionic mechanism underlying recovery of rhythmic activity in adult isolated neurons. J Neurophysiol 96:1860-1876.

Harris-Warrick RM (2011) Neuromodulation and flexibility in Central Pattern Generator networks. Curr Opin Neurobiol 21:685-692.

Hartline DK (1967) Impulse identification and axon mapping of the nine neurons in the cardiac ganglion of the lobster Homarus americanus. J Exp Biol 47:327-340.

Hay M (1998) Cyclosporine A modulation of Ca + + activated K+ channels in cardiac sensory afferent neurons. Brain Res 786:243-247.

Hayashi Y, Shi SH, Esteban JA, Piccini A, Poncer JC, Malinow R (2000) Driving AMPA receptors into synapses by LTP and CaMKII: requirement for GluR1 and PDZ domain interaction. Science 287:2262-2267.

Kennedy MB (1989) Regulation of neuronal function by calcium. Trends Neurosci 12:417-420.

Khorkova O, Golowasch J (2007) Neuromodulators, not activity, control coordinated expression of ionic currents. J Neurosci 27:8709-8718.

Kim M, Baro DJ, Lanning CC, Doshi M, Moskowitz HS, Farnham J, HarrisWarrick RM (1998) Expression of Panulirus shaker potassium channel splice variants. Receptors Channels 5:291-304.

Klee CB, Ren H, Wang X (1998) Regulation of the calmodulin-stimulated protein phosphatase, calcineurin. J Biol Chem 273:13367-13370.

LeMasson G, Marder E, Abbott LF (1993) Activity-dependent regulation of conductances in model neurons. Science 259:1915-1917.

Lin DT, Makino Y, Sharma K, Hayashi T, Neve R, Takamiya K, Huganir RL (2009) Regulation of AMPA receptor extrasynaptic insertion by $4.1 \mathrm{~N}$, phosphorylation and palmitoylation. Nat Neurosci 12:879-887.

MacLean JN, Zhang Y, Johnson BR, Harris-Warrick RM (2003) Activityindependent homeostasis in rhythmically active neurons. Neuron 37:109-120.

MacLean JN, Zhang Y, Goeritz ML, Casey R, Oliva R, Guckenheimer J, Harris-Warrick RM (2005) Activity-independent coregulation of IA and Ih in rhythmically active neurons. J Neurophysiol 94:3601-3617.

Marder E (2011) Variability, compensation, and modulation in neurons and circuits. Proc Natl Acad Sci U S A 108:15542-15548.

Misonou H (2010) Homeostatic regulation of neuronal excitability by $\mathrm{K}(+)$ channels in normal and diseased brains. Neuroscientist 16:51-64.

Misonou H, Trimmer JS (2004) Determinants of voltage-gated potassium channel surface expression and localization in Mammalian neurons. Crit Rev Biochem Mol Biol 39:125-145.

Misonou H, Mohapatra DP, Park EW, Leung V, Zhen D, Misonou K, Anderson AE, Trimmer JS (2004) Regulation of ion channel localization and phosphorylation by neuronal activity. Nat Neurosci 7:711-718.

Misonou H, Mohapatra DP, Trimmer JS (2005) Kv2.1: a voltage-gated k+ channel critical to dynamic control of neuronal excitability. Neurotoxicol 26:743-752.

Nerbonne JM, Gerber BR, Norris A, Burkhalter A (2008) Electrical remodelling maintains firing properties in cortical pyramidal neurons lacking KCND2-encoded A-type K+ currents. J Physiol 586:1565-1579.

O'Leary T, van Rossum MC, Wyllie DJ (2010) Homeostasis of intrinsic excitability in hippocampal neurones: dynamics and mechanism of the response to chronic depolarization. J Physiol 588:157-170.

Ross WN (1989) Changes in intracellular calcium during neuron activity. Annu Rev Physiol 51:491-506.
Rüegg UT, Burgess GM (1989) Staurosporine, K-252 and UCN-01: potent but nonspecific inhibitors of protein kinases. Trends Pharm Sci 10:218-220.

Sakurai A, Wilkens JL (2003) Tension sensitivity of the heart pacemaker neurons in the isopod crustacean Ligia pallasii. J Exp Biol 206:105-115.

Schulz DJ, Goaillard JM, Marder E (2006a) Variable channel expression in identified single and electrically coupled neurons in different animals. Nat Neurosci 9:356-362.

Schulz DJ, Baines RA, Hempel CM, Li L, Liss B, Misonou H (2006b) Cellular excitability and the regulation of functional neuronal identity: from gene expression to neuromodulation. J Neurosci 26:10362-10367.

Schulz DJ, Goaillard JM, Marder EE (2007) Quantitative expression profiling of identified neurons reveals cell-specific constraints on highly variable levels of gene expression. Proc Natl Acad Sci U S A 104:13187-13191.

Tazaki K, Cooke IM (1979) Isolation and characterization of slow, depolarizing responses of cardiac ganglion neurons in the crab, Portunus sanguinolentus. J Neurophysiol 42:1000-1021.

Tazaki K, Cooke IM (1983a) Separation of neuronal sites of driver potential and impulse generation by ligaturing in the cardiac ganglion of the lobster, Homarus americanus. J Comp Physiol A Neuroethol Sens Neural Behav Physiol 151:329-346.

Tazaki K, Cooke IM (1983b) Neuronal mechanisms underlying rhythmic bursts in crustacean cardiac ganglia. Symp Soc Exp Biol 37:129-157.

Tazaki K, Cooke IM (1983c) Topographical localization of function in the cardiac ganglion of the crab, Portunus sanguinolentus. J Comp Physiol A Neuroethol Sens Neural Behav Physiol 151:311-328.

Temporal S, Desai M, Khorkova O, Varghese G, Dai A, Schulz DJ, Golowasch J (2012) Neuromodulation independently determines correlated channel expression and conductance levels in motor neurons of the stomatogastric ganglion. J Neurophysiol 107:718-727.

Thoby-Brisson M, Simmers J (1998) Neuromodulatory inputs maintain expression of a lobster motor pattern-generating network in a modulationdependent state: evidence from long-term decentralization in vitro. J Neurosci 18:2212-2225.

Thoby-Brisson M, Simmers J (2002) Long-term neuromodulatory regulation of a motor pattern-generating network: maintenance of synaptic efficacy and oscillatory properties. J Neurophysiol 88:2942-2953.

Tobin AE, Cruz-Bermudez ND, Marder E, Schulz DJ (2009) Correlations in ion channel mRNA in rhythmically active neurons. PLoS One 4:e6742.

Tsunoda S, Salkoff L (1995) The major delayed rectifier in both Drosophila neurons and muscle is encoded by Shab. J Neurosci 15:5209-5221.

Turrigiano G (2011) Too many cooks? Intrinsic and synaptic homeostatic mechanisms in cortical circuit refinement. Annu Rev Neurosci 34:89-103.

Turrigiano G (2012) Homeostatic synaptic plasticity: local and global mechanisms for stabilizing neuronal function. Cold Spring Harb Perspect Biol 4:a005736.

Turrigiano G, Abbott LF, Marder E (1994) Activity-dependent changes in the intrinsic properties of cultured neurons. Science 264:974-977.

Turrigiano G, LeMasson G, Marder E (1995) Selective regulation of current densities underlies spontaneous changes in the activity of cultured neurons. J Neurosci 15:3640-3652.

Zhu JJ, Esteban JA, Hayashi Y, Malinow R (2000) Postnatal synaptic potentiation: delivery of GluR4-containing AMPA receptors by spontaneous activity. Nat Neurosci 3:1098-1106. 